molecules. The cornerstone of today's view, developed by the third Baron Rayleigh, is that light is scattered by the molecules of the air, principally nitrogen and oxygen. The interaction of these molecules with electromagnetic radiation leads to some of the light being diverted from its original path and re-radiated isotropically. This process is known as Rayleigh scattering, and its efficiency increases as the fourth power of the frequency - very sharply. Wavelength is inversely proportional to frequency, so shorter wavelengths are scattered much more than longer ones: blue much more than red.

Marian Smoluchowski reached similar conclusions in a different way, basing his argument on the opalescence of carbon dioxide near its critical point, as observed by Einstein and Thomas Andrews. One last point worth making is that the scattering in our atmosphere that makes the sky blue requires the molecules to act independently of each other - the scattering has to be incoherent. If the density of the atmosphere were too high, the scattering would be multiple and coherent (the latter occurs in transparent solids), so the colour would be lost. With too low a density, there would be too little scattering to be registered by the eye.

Pesic has a broadly based erudition and the science in his book is pretty sound. I do not agree entirely with his account of the excitation of the airglow, and I know that Earth is not 10 billion years old, but these are small matters. A huge amount of important science is presented in an accessible way that makes no huge demands on non-scientist readers, and the level and approach provide enough intellectual substance for the specialist. Copious notes flesh out many of the points made in the main text. The notes are preceded by an interesting selection of letters between George
Stokes, Tyndall and Lord Kelvin on the blue of the sky. Many of the concepts developed are taken for granted by almost everyone and are deeply ingrained in the very heart of modern science. Science does not always proceed in a linear or expected fashion, being helped forward in some cases by inspiration. As Pesic says of a prose poem by Edgar Allen Poe dedicated to Alexander von Humboldt: "a visionary was able to discern a conclusion vindicated only much later by sober science".

I commend this book to those who want to read about truly significant discoveries linked together through a need to answer what seems to be a simple question. Unlike many other attempts to popularize science, this book has managed not to garble the facts or sensationalize them. It is well worth reading.

Richard P. Wayne is in the Department of Chemistry, University of Oxford, South Parks Road, Oxford OX13QZ, UK.

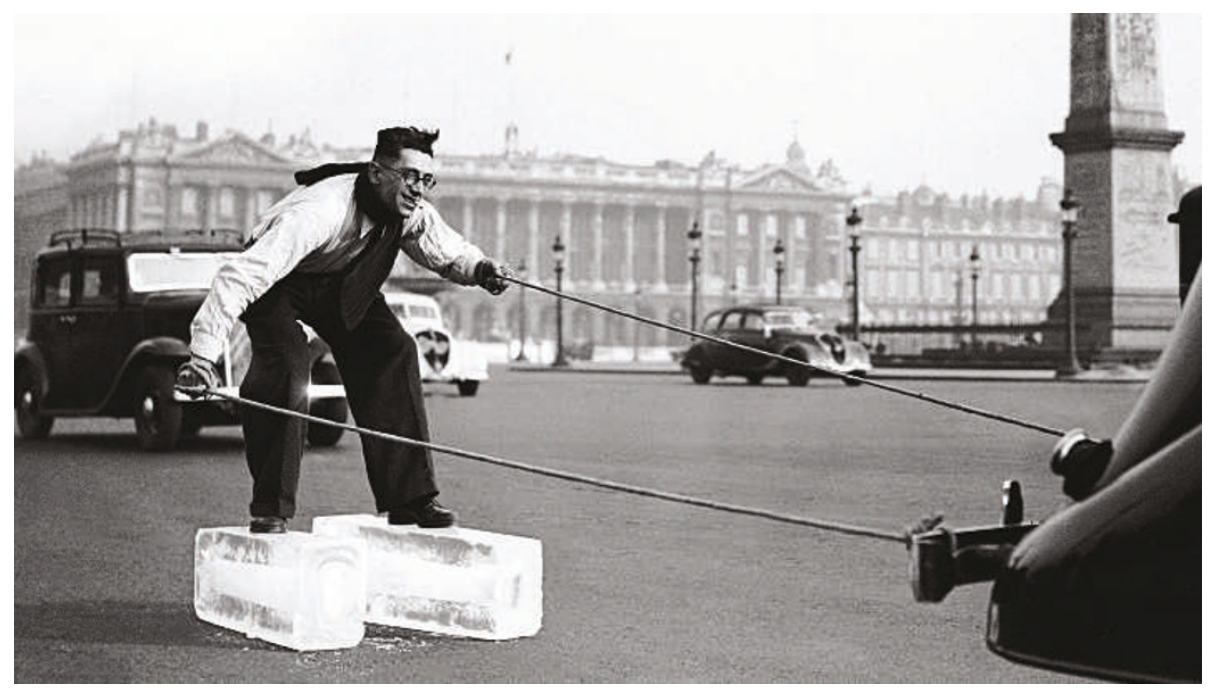

Smooth operator: a man takes advantage of the properties of ice to hitch a lift in 1930s Paris.

\title{
The big freeze
}

\section{Ice: The Nature, the History and the Uses of an Astonishing Substance \\ by Mariana Gosnell \\ Alfred A. Knopf: 2005. 576 pp. $\$ 30$}

\section{Greg Dash}

In its various forms, solid $\mathrm{H}_{2} \mathrm{O}$ covers large parts of Earth's surface for all or much of the year, with implications for our climate. The reflectivity of snow and sea ice greatly influences the planet's heat budget, with any reduction in coverage providing a positive-feedback mechanism for global warming. In her book Ice, Mariana Gosnell quotes some researchers' gloomy predictions: "Nobody knows how to stop the warming of the Earth." Yet there are enough interactions in the system for some effects, such as increased precipitation, to perhaps counteract the warming. Still, Gosnell's book isn't only about the serious topic of global warming; instead she takes a much lighter look at the solid phase of water.

Ice has such diverse properties that it cuts across a range of disciplines. Gosnell's 36 chapters describe the basic science, the importance and the drama for specialists of each, be they glaciologists, atmospheric scientists or students of permafrost, ice coring and ice physics.

One of the most unusual applications was a project to build an unsinkable aircraft carrier. During the early days of the Second World War, Nazi submarines sank a lot of ships crossing the Atlantic from the United States to Britain. Geoffrey Pyke, who was director of programmes for Lord Mountbatten, proposed that a great artificial iceberg be built to serve as a floating base in the Atlantic for submarine-hunting planes. One of the essential features of the project was that the ice would be strengthened with wood pulp. In Pyke's honour, the composite was christened 'pykrete'. Churchill liked the idea, and the project began, with a test model built in Canada. But the project never progressed very far, being made redundant by Allied aircraft with increased range. Max Perutz, who later received a Nobel prize for his work in biochemistry, was a young researcher on the project. Years later he wrote: "I think that had not the course of the war and the state of our armaments changed, the bergship could have been constructed." It would surely have been the world's largest ice sculpture.

Gosnell writes of the start of her interest in ice. She had been sent as a journalist to report on an expedition to the Canadian high Arctic, where tests were being done to quantify the damage that floating ice might cause to tankers or oil rigs. Intrigued by what she learned, she began to read a lot about ice. The book's bibliography is impressive, and I get the impression she has read a good deal of the listed articles. Most of the chapters are written with clear descriptions and understanding.

At least one of the chapters comes out of Gosnell's personal experience. She writes: "One winter I rented a cabin in Elkins, New Hampshire, to watch a lake freeze." After waiting through windy days and fluctuating temperatures, the event finally happens. "In one small, secluded spot... I see, in a bay where the beach slopes gently into the lake and the water is only a few inches deep, what looks like a windowpane. I am excited out of all proportion to the event. First lake ice!"

All the chapters are written with similar life and imagery. As a result, the book will make for enjoyable reading by specialists and nonspecialists alike.

Greg Dash is emeritus professor in the

Department of Physics, University of Washington, Seattle, Washington 98195, USA. 